\title{
A possible characterization of suffusion susceptibility independent of the hydraulic loading history?
}

\author{
A. Rochim*, D. Marot \\ Nantes Université, Institut de Recherche en Génie Civil et Mécanique, GeM, France \\ * Sultan Agung Islamic University, Civil Engineering Department, Indonesia \\ L. Sibille \\ Université Grenoble Alpes, 3SR Laboratory, France
}

V.T. Le

Nantes Université, Institut de Recherche en Génie Civil et Mécanique, GeM, France

\begin{abstract}
Suffusion is a complex phenomenon which involves selective erosion of fine particles under the effect of seepage flow in the matrix of coarser particles. With the objective to characterize suffusion susceptibility, a series of downward seepage flow tests was realized with a triaxial erodimeter developed in our laboratory. Three different cohesionless soils were tested under controlled hydraulic gradient or under controlled flow rate. This study shows the significant effect of hydraulic loading history on the value of critical hydraulic gradient. Moreover, method characterizing the erosion susceptibility based on rate of erosion doesn't lead to a unique characterization of suffusion process for different histories of hydraulic loading. The new analysis is based on energy expended by the seepage flow to characterize the hydraulic loading and the cumulative eroded dry mass to characterize the soil response. The results demonstrate that this approach is effective to characterize suffusion susceptibility for cohesionless soils.
\end{abstract}

\section{INTRODUCTION}

Hydraulic structures such as dams and levees or dikes provide many benefits for our society. They are built with the aim to protect people and property against flood and to provide water supply and the need of electricity. Since hydraulic earth structures are subjected to some seepage passing through them, this can lead a generation of the detachment and transport of certain constituent particles of the structures or their foundations. In the worst cases, it may lead to failure. This process is called internal erosion. Floods resulting from the failure of hydraulic structures can produce some devastating disasters, not only certain property damage but also loss of life.

The complex phenomenon of suffusion is one of the main internal erosion processes (Fell and Fry, 2013). It corresponds to the process of detachment and then transport of the finest soil particles within the porous network constituted by the soil itself. However a fraction of the detached particles can resettle or be filtered in the bulk of the porous network. This process can eventually induce local clogging. The processes of detachment, transport and filtration of fine particles are thus inseparable. Although the suffusion development may be difficult to detect in situ, it has to be considered with attention as it can evolve towards a second phase of erosion, characterized by a blowout and an important washing out of fine particles, inducing both a large settlement of specimen and a relatively strong increase in the hydraulic conductivity (Sibille et al., 2015a). Thus to ensure the safety assessment of hydraulic earth structures, the characterization of suffusion susceptibility is required. However, to the present, the classification of soil susceptibility due to suffusion is far to be completed.

With the objective to improve the characterization of suffusion susceptibility, a series of onedimensional downward seepage flow tests was realized with a specific erodimeter developed in our laboratory (Bendahmane et al., 2008). Three different gap graded cohesionless soils were tested under controlled hydraulic gradient or under controlled flow rate. The results are discussed in terms of hydraulic loading history effects on the value of critical hydraulic gradient and on the rate of erosion. A new analysis is based on energy expended by the seepage flow to characterize the hydraulic loading and the cumulative eroded dry mass to characterize the soil response.

\section{CONTROL PARAMETERS FOR LIKELIHOOD OF SUFFUSION}

According to Garner and Fannin (2010) three factors affect the initiation of internal erosion processes: the sensitivity of the material, the condition of critical stress and the critical hydraulic load. In the same manner, Fell and Fry (2013) distinguished three cri- 
teria for suffusion to occur: (i) the size of the fine soil particles must be smaller than the size of the constrictions between the coarser particles, which form the basic skeleton of the soil. (ii) The amount of fine soil particles must be less than enough to fill the voids of the basic skeleton formed by the coarser particles, and (iii) the velocity of flow through the soil matrix must be high enough to move the loose fine soil particles through the constrictions.

The first two criteria are associated with geometric conditions that may control the likelihood for suffusion. The fabric of granular soils, first depends on the grain size distribution. Thus to assess the susceptibility of a soil to suffusion, several researchers have proposed methods only based on the study of the soil gradation (Kenney \& Lau, 1985; Li \& Fannin, 2008; Chang \& Zhang, 2013 among others). However, the modification of the effective stress can induce grain rearrangements and then can also influence the suffusion susceptibility. Moffat \& Fannin (2006) and Bendahmane et al. (2008) showed that a rise in the mean effective stress causes an increase of the soils' resistance to suffusion, whereas the increase of deviatoric stress produces an increase of the maximum erosion rate (Chang \& Zhang, 2011). Finally for a given grain size distribution and a given effective stress, angularity of coarse fraction grains contributes to increase the suffusion resistance (Marot et al., 2012).

The third criterion is related to the action of the fluid phase with respect to seepage loading required to detach and then to transport the fine particles. Skempton \& Brogan (1994) and more recently Ke \& Takahashi (2012) proposed to relate the onset of suffusion with an increase of hydraulic conductivity. The hydraulic loading which produces the onset of suffusion is often described by the critical hydraulic gradient. By carrying out tests on mixtures of sand and gravel with an upward flow, Skempton \& Brogan (1994) concluded that the value of the critical gradient of the suffusion initiation, named $i_{c r}$, is far lower of the value of the critical heave gradient $i_{c}$ (with $i_{c}=\gamma^{\prime} / \gamma_{\mathrm{w}}, \gamma^{\prime}$ : submerged unit weight of the soil specimen and $\gamma_{\mathrm{w}}$ : unit weight of water).

The filtration of some detached particles can induce a clogging process within the soil accompanied with the decrease of the hydraulic conductivity (Reddi et al. 2000; Bendahmane et al. 2008; Marot et al. 2009; 2011a; Nguyen et al. 2012; Luo et al., 2013), which in turn leads to a decrease of the seepage velocity. Therefore, variations of both seepage velocity and pressure gradient have to be taken into account to evaluate the hydraulic loading.

By considering these both parameters, Reddi et al. (2000) assumed that hydraulic loading can be represented by the viscous shear stress at fluid-solid interface. They expressed this shear stress for a horizontal flow between an upstream section $A$ and a downstream section B of the porous medium which is represented by a system of parallel capillary tubes each of a constant radius $r$.

The expression of hydraulic shear stress $\tau$ can be reformulated in the case of a vertical flow by the equation:

$$
\tau=\left(\frac{\Delta h \gamma_{\mathrm{w}}}{\Delta z}\right) \frac{r}{2}
$$

where $\Delta h$ is the drop of hydraulic head between sections $\mathrm{A}$ and $\mathrm{B}, \Delta z=z_{A}-z_{B}\left(z_{A}\right.$ and $z_{B}$ are altitudes of sections $A$ and $B$ respectively).

In the case of cohesive soils, Reddi et al. (2000) proposed to estimate the typical radius of pores by:

$r=\sqrt{\frac{8 k \eta}{n \gamma_{\mathrm{w}}}}$

where $n$ is the porosity, $k$ is the hydraulic conductivity and $\eta$ the dynamic viscosity.

Consequently, the hydraulic shear stress along vertical system of capillary tubes can be expressed by:

$$
\tau=\left(\frac{\Delta h}{\Delta z}\right) \sqrt{\frac{2 k \eta \gamma_{\mathrm{w}}}{n}}
$$

Another way to consider variations of both seepage velocity and pressure gradient consists to express the power expended by the seepage flow (Marot et al. 2011b; Regazzoni \& Marot 2013). Three assumptions are used: the fluid temperature is assumed constant, the system is considered as adiabatic and only a steady state is considered. The energy conservation equation permits to express the total flow power as the summation of the power transferred from the fluid to the solid particles and the power dissipated by viscous stresses in the fluid. As the transfer appears negligible in suffusion case and viscous dissipation of energy representative of fluidsolid interactions (Sibille et al. 2015b), the authors suggest to characterize the fluid loading from the total flow power, $P_{\text {flow }}$ which is expressed by:

$$
P_{\text {flow }}=Q \gamma_{\mathrm{w}} \Delta h
$$

where $Q$ is the fluid flow rate.

The expended energy $E_{\text {flow }}$ is the time integration of the instantaneous power dissipated by the water seepage for the test duration. 


\section{LABORATORY EXPERIMENTS}

\subsection{Main characteristics of testing apparatus}

An erodimeter was designed to apply downward seepage flow on intact fine soil samples or on reconstituted fine soil specimens $(50 \mathrm{~mm}$ in diameter and height up to $100 \mathrm{~mm}$ ) (see Figure 1). A detailed description of the device is reported in Bendahmane et al. (2008) and a brief summary is provided hereafter.

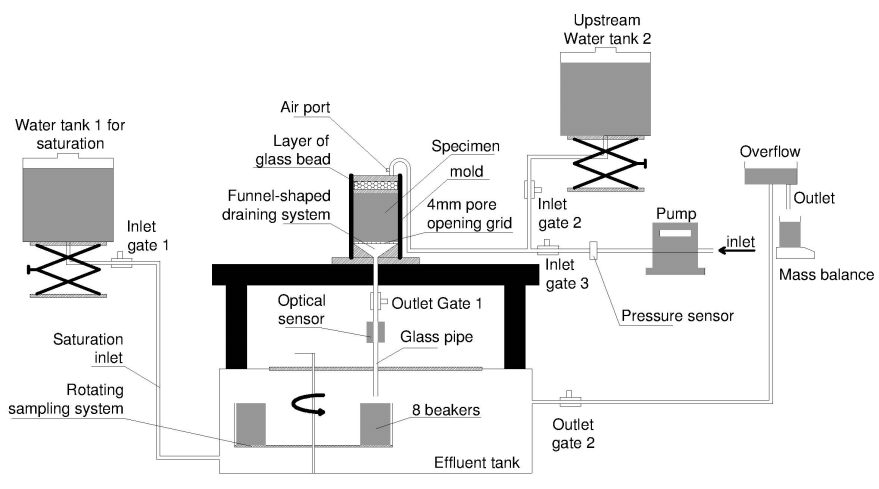

Figure 1. Schematic diagram of the dedicated erodimeter.

The hydraulic gradient of this seepage is controlled by an injection cell equipped with pressure sensor, and connected to an air/water interface cylinder. The system to generate seepage flow in flowrate-controlled conditions comprises a gear pump connected to a pressure sensor at its outlet. The fluid passes through the top cap of the specimen which contains a layer of glass beads to diffuse the fluid uniformly on the specimen top surface. The funnelshaped draining system is connected to an effluent tank by a glass pipe. The effluent tank is equipped with an overflow outlet (to control the downstream hydraulic head) and a rotating sampling system containing 8 beakers for the sampling of eroded particles carried with the effluent. In the case of clay or silt suffusion, a multi-channel optical sensor can be placed around the glass pipe (Marot et al. 2011a), and thanks to a preliminary calibration, clay or silt concentration in the effluent can be computed. At the overflow outlet of the effluent tank, water falls in a beaker which is continuously weighed in order to determine injected flow rate. The sample is supported by a lower mesh screen and the mesh screen opening size is selected with the objective to reproduce the situation of an earth structure without filter, as a dike for example.

\subsection{Soils properties and test procedure}

Three gap graded soils, composed of sand and gravel were tested. A laser diffraction particle-size analyser was used to measure the grain size distribution of these soils (see Figure 2). Tests were performed with demineralised water and without deflocculation agent. Table 1 summarizes the soils used in the laboratory tests and their properties.

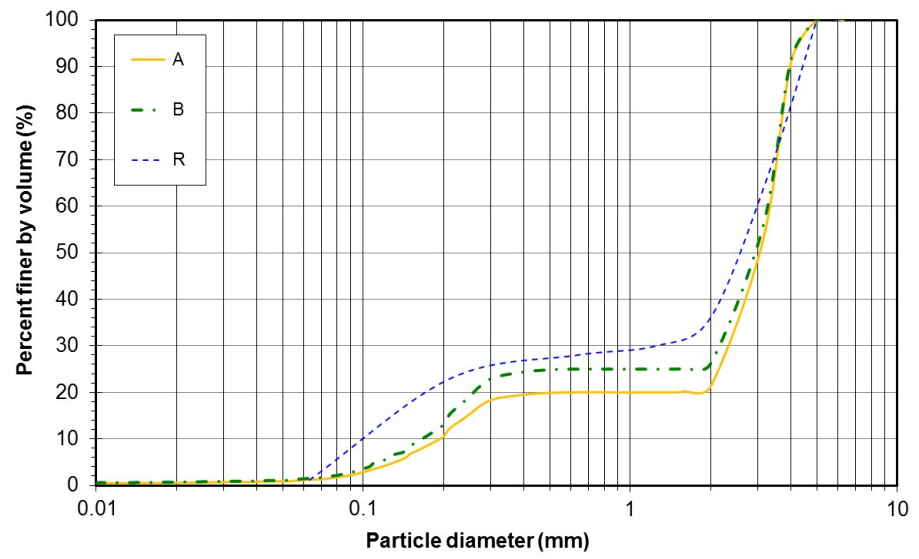

Figure 2. Grain size distribution of tested soils.

Table 1. Properties of tested gradations.

\begin{tabular}{lccc}
\hline & \multicolumn{3}{c}{ Tested gradations } \\
Properties & $\mathrm{A}$ & $\mathrm{B}$ & $\mathrm{R}$ \\
\hline$P(\%)$ & 1.23 & 1.53 & 1.20 \\
$G_{r}$ & 3.2 & 3.2 & $\mathrm{WG}$ \\
$C_{u}$ & 17.1 & 19.5 & 24.5 \\
$d_{15} / d_{85}$ & 8.76 & 8.74 & 9.65 \\
$(H / F)_{\min }$ & 0.04 & 0.04 & 0.17 \\
$D(H / F)_{\min }$ & 0.40 & 0.40 & 0.21 \\
$(\mathrm{~mm})$ & & & \\
\hline
\end{tabular}

$P$ : percentage of particle smaller than $0.063 \mathrm{~mm} ; \mathrm{G}_{\mathrm{r}}=\mathrm{d}_{\max } / \mathrm{d}_{\min }$ ( $d_{\max }$ and $d_{\min }$ : maximal and minimal particle sizes characterizing the gap in the grading curve); $C_{u}$ : uniformity coefficient; $\mathrm{d}_{15}$ and $d_{85}$ are the sieve sizes for which $15 \%$ and $85 \%$ respectively of the weighed soil is finer; $F$ and $H$ are the mass percentages of the grains with a size, lower than a given particle diameter $d$ and between $d$ and $4 d$ respectively; $D(H / F)_{\min }$ is the corresponding diameter with the minimum value of ratio $H / F$; WG: widely graded soil.

According to the gradation based criteria proposed by Kenney \& Lau (1985), Li \& Fannin (2008) and Chang \& Zhang (2013), the soils studied here are assessed to be internally unstable.

The specimen preparation phase is divided into three steps: production, installation and then saturation of the specimen. The repeatability of the production is achieved by the following procedure. Sand and gravel are first mixed with a moisture content of $7.8 \%$. The specimens are prepared using a single layer semi-static compaction technique, until the initial fixed dry density $\left(17.39 \mathrm{kN} / \mathrm{m}^{3}\right)$ is reached with $50 \mathrm{~mm}$ specimen height. As recommended by Kenney \& Lau (1985), in order to reduce preferential flow, each specimen is wrapped in a latex sleeve, then closed inside a metal mould. The downstream filter is constituted by a $4 \mathrm{~mm}$ pore opening grid. This pore opening allows the migration of all parti- 
cles of sand as in the case of an earth structure without any filter. The saturation phase begins with an upward injection of carbon dioxide for 5 minutes duration to improve dissolution of gases into water, and afterward continued by injecting demineralized water under low hydraulic gradient. The saturation process is left for twelve hours and until the water trickled over the top cap. Finally, the specimen is subjected to a downward flow, using demineralized water and under three kinds of hydraulic loading: multi-staged hydraulic gradients, constant hydraulic gradient and constant flow rate. Figure 3 shows the evolution during the time of the applied hydraulic gradients. First multi-staged hydraulic gradient condition (named a) consists of increasing the hydraulic gradient by steps of 0.1 until 2 , then by steps of 0.5 between 2 and 4 and by steps of 1 beyond. For the second kind of hydraulic loading (b), hydraulic gradient increment is directly equal to 1 . For both hydraulic loadings, each stage of hydraulic gradient is kept constant during $10 \mathrm{~min}$. For hydraulic loading (k) increment of hydraulic gradient is 0.5 and the duration of each stage is 12 hours. Hydraulic loading (c) represents a constant hydraulic gradient of 4 $\mathrm{m} / \mathrm{m}$. Finally hydraulic loading (q) corresponds to a constant flow rate $(q=1.641 \mathrm{ml} / \mathrm{min})$.

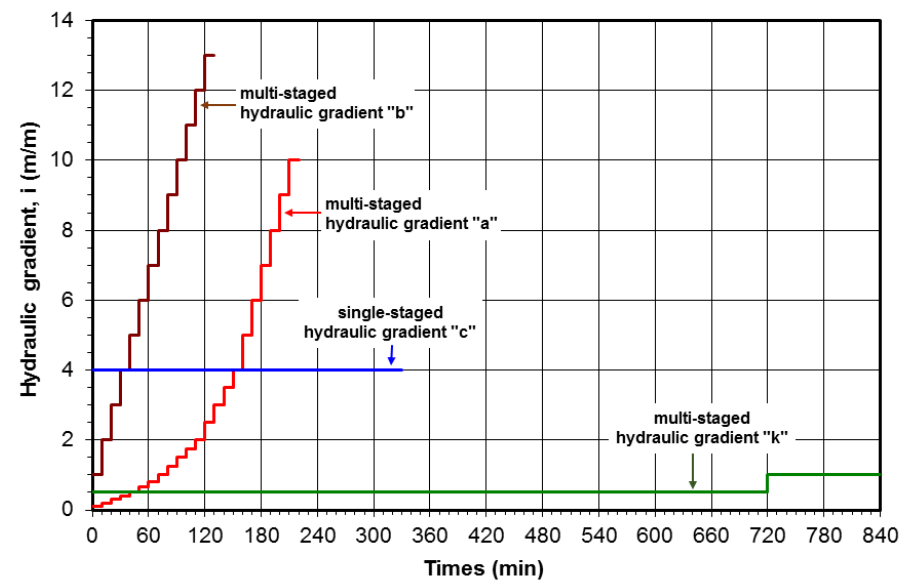

Figure 3. Time evolution of multi-staged and single staged hydraulic gradients.

With the objective to improve the readability, the first letter of each test name is related to the gradation (see Figure 2) and the last letter indicates the type of hydraulic loading type. Table 2 indicates the extreme values of applied hydraulic gradient or injected flow rate as well as the test duration for ten tested specimens.

The repeatability of tests was verified by performing 2 tests in the same conditions: A-a and A-a_rep.
Table 2. Test conditions.

\begin{tabular}{|c|c|c|c|c|}
\hline $\begin{array}{l}\text { Soil } \\
\text { reference }\end{array}$ & $\begin{array}{l}\text { Specimen } \\
\text { reference }\end{array}$ & $\begin{array}{l}\text { Range of } \\
\text { hydraulic } \\
\text { gradient }\end{array}$ & $\begin{array}{c}\text { Injected } \\
\text { flow } \\
(\mathrm{ml} / \mathrm{min})\end{array}$ & $\begin{array}{c}\text { Test } \\
\text { duration } \\
(\min )\end{array}$ \\
\hline \multirow[t]{4}{*}{ A } & A-a & $\begin{array}{c}\text { From } \\
0.1 \text { to } 15\end{array}$ & - & 270 \\
\hline & A-a_rep & $\begin{array}{c}\text { From } \\
0.1 \text { to } 15\end{array}$ & - & 250 \\
\hline & A-b & $\begin{array}{c}\text { From } \\
1 \text { to } 13\end{array}$ & - & 130 \\
\hline & A-c & 4 & - & 300 \\
\hline \multirow[t]{4}{*}{ B } & B-a & $\begin{array}{c}\text { From } \\
0.1 \text { to } 6\end{array}$ & - & 180 \\
\hline & B-c & 4 & - & 300 \\
\hline & B-k & $\begin{array}{c}\text { From } \\
0.5 \text { to } 1\end{array}$ & - & 1440 \\
\hline & B-q & - & 1.641 & 270 \\
\hline \multirow[t]{2}{*}{$\mathrm{R}$} & $\mathrm{R}-\mathrm{a}$ & $\begin{array}{c}\text { From } \\
0.1 \text { to } 6\end{array}$ & - & 180 \\
\hline & R-b & $\begin{array}{l}\text { From } \\
1 \text { to } 8\end{array}$ & - & 80 \\
\hline
\end{tabular}

\section{RESULTS AND IDENTIFICATION OF PREDOMINANT PROCESSES}

\subsection{Hydraulic behavior of tested specimens}

The hydraulic conductivity of tested specimens are shown on Figure 4 in the case of hydraulic loadings (a) and (b) and on Figure 5 for others types of hydraulic loadings.

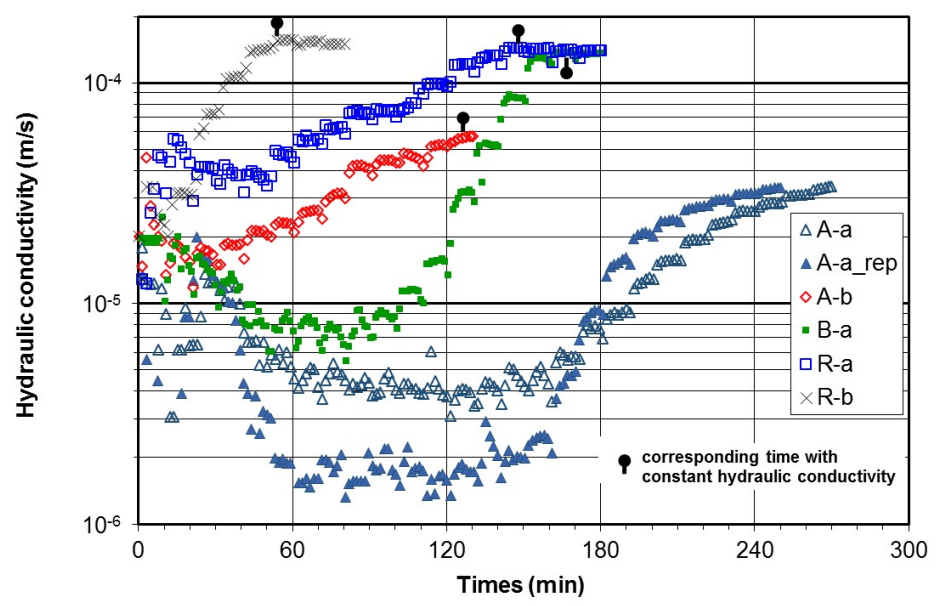

Figure 4. Hydraulic conductivity during suffusion tests, multistaged hydraulic gradient loading. 


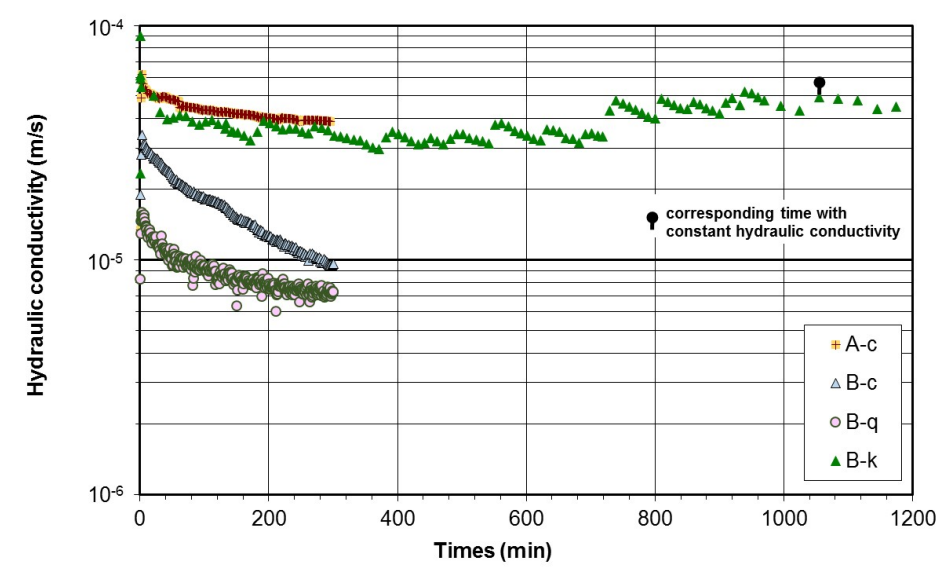

Figure 5. Hydraulic conductivity during suffusion tests, single staged hydraulic gradient or flow rate controlled tests.

Under multi-staged hydraulic gradients, the hydraulic conductivity first decreases with a kinetic depending on the hydraulic loading history. In the case of hydraulic loading (b), the duration of this first decreasing step is from $10 \mathrm{~min}$ (test R-b) to 20 min (test A-b). Whereas under hydraulic loading (a), the hydraulic conductivity decreases for a much longer time ( $50 \mathrm{~min}$ for test R-a; 80 min for test B-a; $120 \mathrm{~min}$ for tests A-a, and A-a_rep). The second phase of hydraulic conductivity evolution is characterized by a rapid increase by a factor ranging from 4 (test A-b) to 20 (test A-a_rep). Finally the hydraulic conductivity reaches a constant value which is pointed out by black spots on Figure 4 and Figure 5.

Figure 5 shows the slow decrease with the time of the hydraulic conductivity which is measured during single staged hydraulic gradient tests (tests A-c, B-c) or under flow rate controlled test (test B-q). Thus some variation in the hydraulic loading appears necessary in order to produce the second increasing phase of the hydraulic conductivity, even after several hours of seepage as during test B-k. During this test, the hydraulic gradient was increased at $\mathrm{t}=720 \mathrm{~min}$ (see Figure 3).

\subsection{Erosion rate and predominant processes}

Considering the surface of pores is more representative than surface of the cross section of the sample for suffusion process, Reddi et al. (2000) expressed the erosion rate of soils per unit pore area by:

$$
\dot{m}=\frac{m(\Delta t)}{N_{p} S_{p} \Delta t}
$$

where $m$ is eroded dry mass during the elapsed time $\Delta t, N_{p}$ the number of pores, and $S_{p}$ the average area of a single pore. Assuming an average pore radius $r$ as defined in Eq.2, $N_{p}$ and $S_{p}$ can be computed respectively by:
$N_{p}=\frac{S n}{\pi r^{2}}$

$S_{p}=2 \pi r L$

where $S$ is the cross section area of the specimen and $L$ its length.

Erosion rate as defined in equation (5) is displayed in Figures 6 and 7.

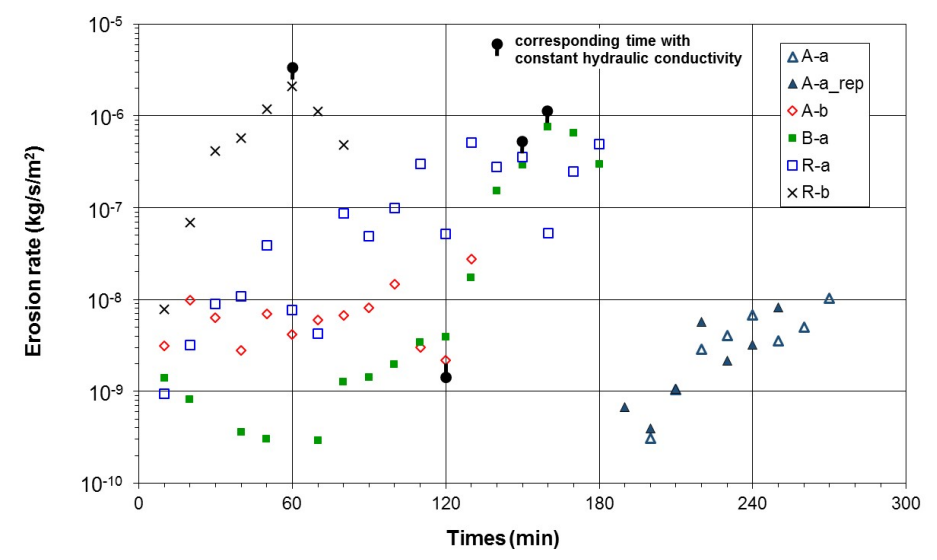

Figure 6. Time evolution of erosion rate, multi-staged hydraulic gradient.

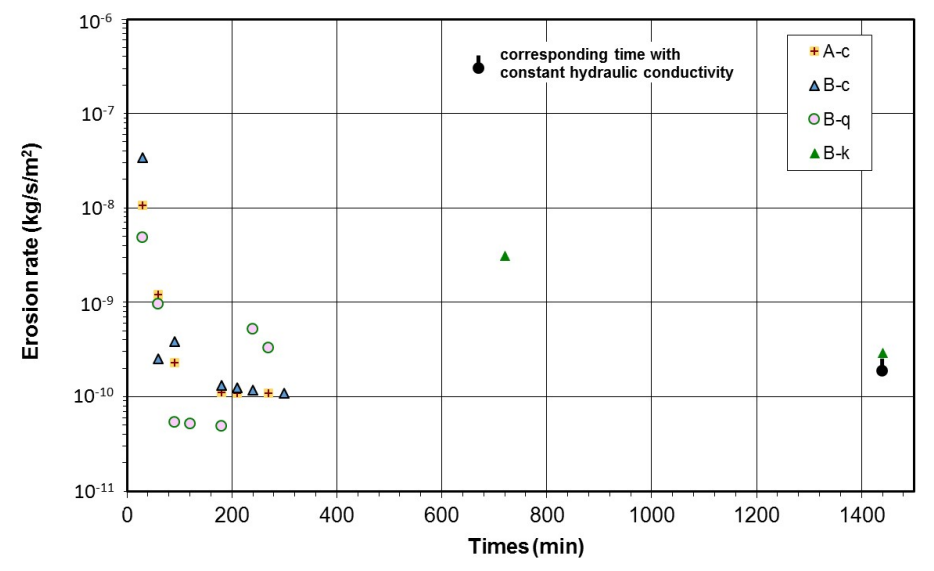

Figure 7. Time evolution of erosion rate, single staged hydraulic gradient or flow rate controlled tests.

The decrease of hydraulic conductivity is systematically accompanied with a decrease of erosion rate, which suggests that some detached particles may be filtered within the soil itself. This filtration may induce a clogging of several pores and then a decrease of the hydraulic conductivity. In multi-staged hydraulic gradient condition, a rough increase of the erosion rate then occurs simultaneously with the increase of the hydraulic conductivity, confirming the assumption of a clogging firstly restricting the water flow and then blown by the seepage flow itself. Thus the predominant process during this second phase seems to be the detachment and transport of solid particles. Finally hydraulic conductivity tends to stabilize while the erosion rate decreases again. This 
third phase could be explained by the presence of preferential flows created by the erosion process (along which fine particles have been almost all washed) and leading to a steady state. It is worth noting that for a given soil, a more severe multi-staged hydraulic loading induces a higher final value of hydraulic conductivity. Final hydraulic conductivity is higher under hydraulic loading (b) than under hydraulic loading (a) (tests A-a, A-a_rep, A-b, R-a and $\mathrm{R}-\mathrm{b}$ on Figure 4) and itself higher than in the case of hydraulic loading (k) (test B-a on Figure 4 and test B-k on Figure 5).

Therefore, these results show that the history of the hydraulic loading has a significant influence on the hydraulic behavior of the specimens and on the development of the suffusion. For a given soil, a value of the hydraulic gradient $i$ can lead to the predominant process of filtration in the case of single staged hydraulic loading (for example, test B-c, $i=$ constant $=4$ ); whereas in a multi-staged hydraulic gradient test, this same hydraulic gradient value is associated with a steady state following an important erosion phase. For instance, for the test B-a, the final steady state is reached for $i=4$ (see Figure 4). Finally, the complex erosion phenomenon of suffusion appears as a combination of 3 processes: detachment, transport and possible filtration of finer fraction.

\section{DISCUSSION}

\subsection{Onset of suffusion}

Skempton \& Brogan (1994) proposed to define the onset of suffusion by an increase of hydraulic conductivity and they defined the corresponding hydraulic loading by the hydraulic gradient. Figure 8 shows the flow velocity versus the hydraulic gradient for tests on soil A, and Figure 9 for other tests.

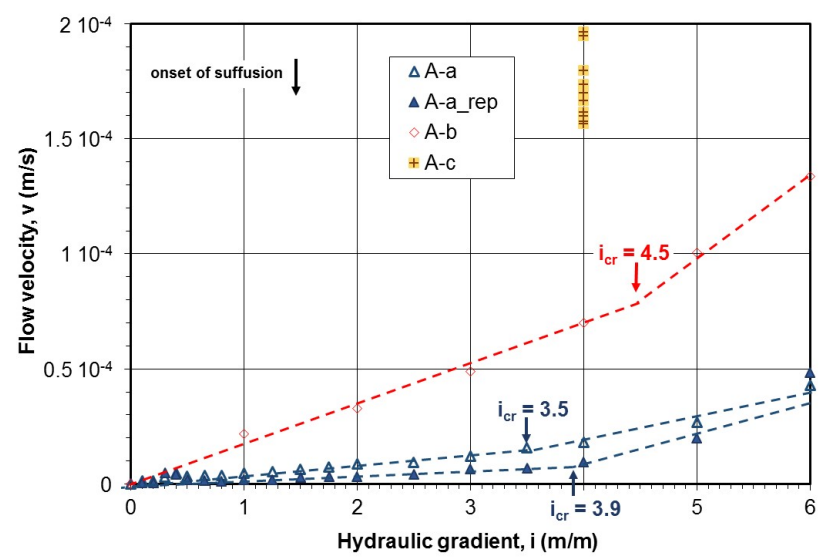

Figure 8. Definition of the critical hydraulic gradient for soil A in the plane flow velocity versus hydraulic gradient.

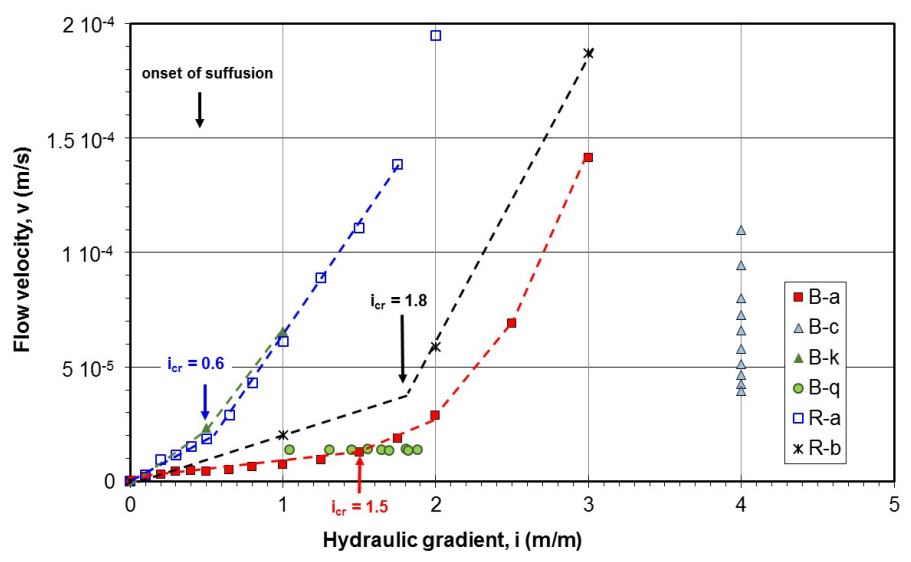

Figure 9. Definition of the critical hydraulic gradient for soils B and $\mathrm{R}$ in the plane flow velocity versus hydraulic gradient.

First, it can be observed that under single staged hydraulic gradient condition (test A-c on Figure 8, test B-c on Figure 9) and under flow rate controlled condition (test B-q on Figure 9), the determination of the suffusion onset with such approach appears not possible. For tests realized under multi staged hydraulic gradient conditions, the critical hydraulic gradient appears smaller with the hydraulic loading (a) than with the hydraulic loading (b). For soil A, $i_{c r}$ is comprised between 3.5 and 3.9 under (a) loading and $i_{c r}=4.5$ under (b) loading. For soil $\mathrm{R}, i_{c r}=0.6$ under (a) loading and 1.8 under (b) loading. In consequence, for a given soil the critical hydraulic gradient seems to depend on the history of hydraulic loading. This influence of hydraulic loading history was also observed by Luo et al. (2013) who compared the results obtained with two test durations. They notably concluded that a long-term large hydraulic head reduces the hydraulic gradient needed for large suffusion development.

\subsection{Development of suffusion}

A commonly used interpretative method for hole erosion test (Wan \& Fell 2004) and for jet erosion test (Hanson \& Simon 2001) consists to describe the erosion rate from the excess shear stress equation, defined by:

$$
\dot{m}=k_{d}\left(\tau-\tau_{c}\right) \quad \text { for } \tau \geq \tau_{c}
$$

where $k_{d}$ is the erosion coefficient, and $\tau_{c}$ is the critical hydraulic shear stress.

Thus a first interpretative method for suffusion test could be to represent the erosion rate as a function of the hydraulic shear stress. Figures 10 and 11 show the erosion rate (computed by Equation 5) versus the hydraulic shear stress (Equation 3) for all realized tests.

Now we consider tests realized under hydraulic loadings (a) and (b). Only the development phase of suffusion, assumed to start from the aforementioned identification of suffusion onset based on hydraulic 
conductivity increase and finishing at the stabilization of the hydraulic conductivity is taken into account.

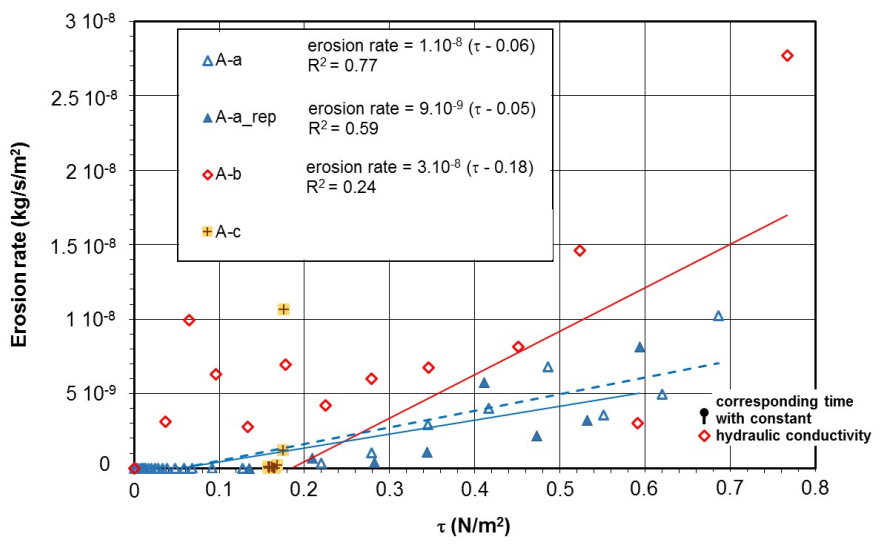

Figure 10. Erosion rate versus hydraulic shear stress, soil A.

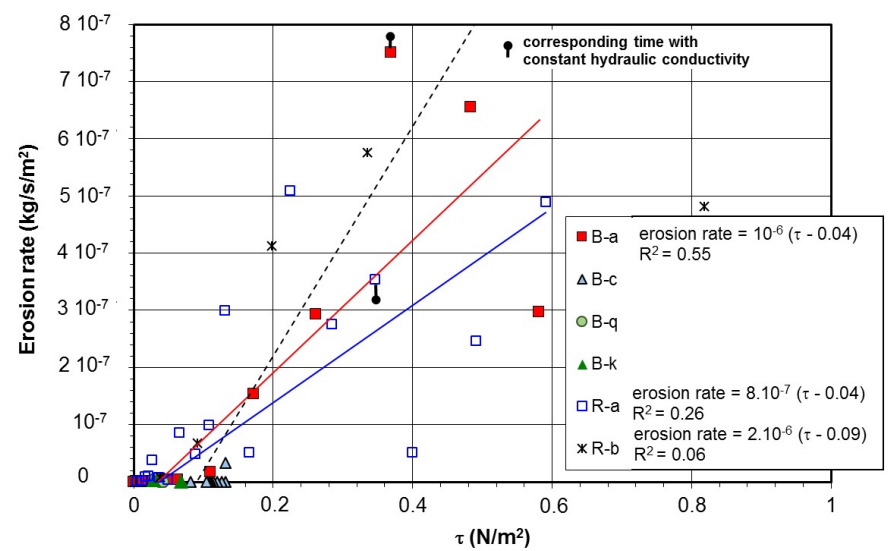

Figure 11. Erosion rate versus hydraulic shear stress, soils B and $\mathrm{R}$.

From this initiation, a linear approximation representing Equation 8 is performed. The corresponding equation and values of $k_{d}, \tau_{c}$ and correlation coefficient $R^{2}$ are shown on Figures 10 and 11. First, it is worth noting the weak values of correlation coefficient (between 0.06 for test R-b, and 0.77 for test Aa) which highlight the low accuracy of this approach. Moreover, the erosion coefficient values obtained with hydraulic loading (a) are systematically smaller than in the case of hydraulic loading (b): $k_{d}=10^{-8} \mathrm{~s} / \mathrm{m}$ and $k_{d}=310^{-8} \mathrm{~s} / \mathrm{m}$ for tests A-a and A-b respectively, $k_{d}=810^{-7} \mathrm{~s} / \mathrm{m}$, and $k_{d}=210^{-6} \mathrm{~s} / \mathrm{m}$ for tests R-a and R$\mathrm{b}$ respectively. Thus the characterization of suffusion susceptibility based on this interpretative method depends on the history of hydraulic loading. Moreover, in the case of flow rate controlled condition tests (B-q on Figure 11) and single staged hydraulic gradient tests (A-c on Figure 10; B-c on Figure 11) and even under hydraulic loading (k) (B-k on Figure 11), it is not possible to describe the erosion rate by such interpretative method.

As the history of hydraulic loading has a strong influence on the specimen hydraulic behavior and also on the suffusion development, the energy expend- ed by the seepage flow $E_{\text {flow }}$ during the suffusion test is determined by the time integration of total flow power, $P_{\text {flow }}$ (computed by Equation 4). The corresponding erosion is represented by the cumulative loss dry mass. Figures 12 and 13 show the cumulative loss dry mass, $m_{d r y}$, versus the cumulative expended energy for all kinds of hydraulic loading and for the whole duration of tests.

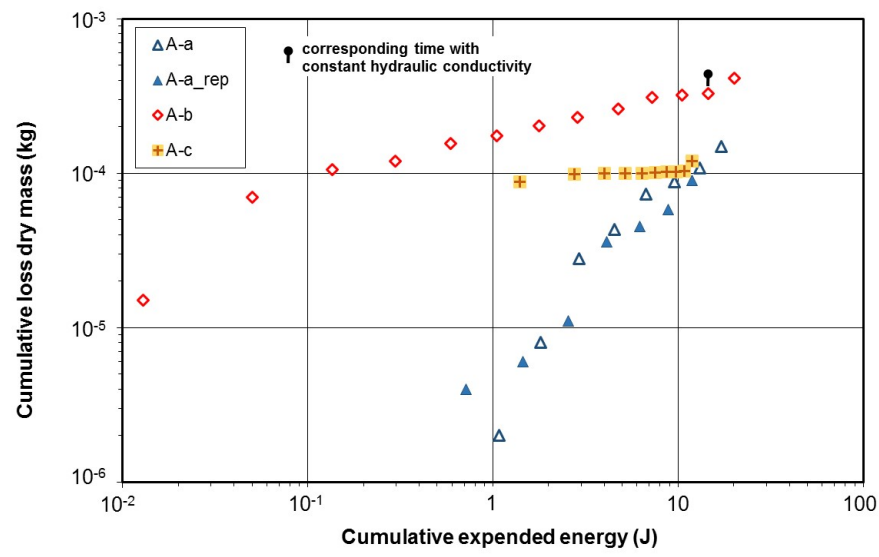

Figure 12. Cumulative loss dry mass versus cumulative expended energy, soil A.

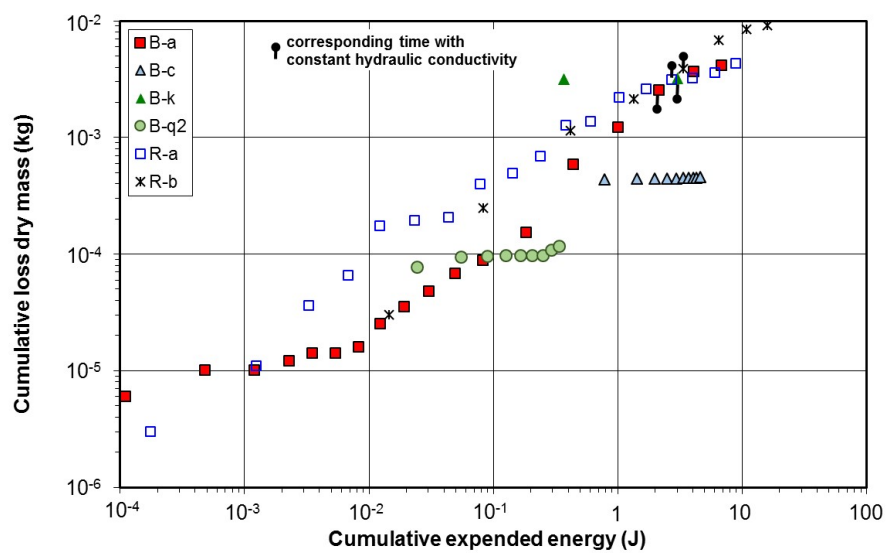

Figure 13. Cumulative loss dry mass versus cumulative expended energy, soils B and R.

Finally at the end of each test, which corresponds to the invariability of the hydraulic conductivity (black spots in Figures 12 and 13 show time of stabilization of hydraulic conductivity), the erosion sensibility can be evaluated by the position on the chart loss dry mass vs expended energy. It is worth noting that for a given soil, when the stabilization of the hydraulic conductivity is reached, the corresponding position on the chart is roughly the same (see on Figure 13, tests B-a and B-k on one hand, tests R-a and $\mathrm{R}-\mathrm{b}$ on the other hand).

In the contrary, if the test is stopped before the stabilization of the hydraulic conductivity (tests A-c, A-a and A-a rep on Figure 12, tests B-c and B-q on Figure 13), the interpretation may lead to an overestimation of the soil resistance (i.e. for a given energy the corresponding eroded mass appears smaller).

This remark shows the necessity to perform suffusion tests by increasing the applied hydraulic gra- 
dient in order to have the possibility to follow the development of all possible processes and to continue the test as far as hydraulic conductivity becomes constant.

\section{CONCLUSION}

The characterization of suffusion susceptibility is an important issue for contributing to the safety assessment of hydraulic earth structures. Tests realized under different hydraulic loading histories highlight the complexity of suffusion which appears as the result of coupling effect of three processes: detachment, transport and filtration. According to the type of hydraulic loading, the predominant process can be either filtration or erosion. Thus even if a transport of particles is geometrically possible, the action of hydraulic loading must be studied.

A seepage test by imposing fluid flow is conducted with the aim to characterize the soil susceptibility. The analysis of the suffusion onset can be carried out by determining the critical hydraulic gradient. However, the realized study shows that the type of hydraulic loading can substantially modify the value of critical hydraulic gradient at which suffusion occurs. For other erosion processes, the interpretative method can consist to describe the erosion rate by using the excess shear stress equation. However in the case of suffusion, the history of hydraulic loading has a strong influence on the hydraulic behavior of the specimens and on the erosion coefficient. Thus it appears very difficult to determine an accurate suffusion susceptibility by this interpretative method.

A new interpretative method is proposed, linking the cumulative eroded dry mass to the energy dissipated by the fluid flow. This method is efficient to determine the suffusion susceptibility for cohesionless material. This study also shows the necessity to perform suffusion tests by increasing the applied hydraulic gradient and to continue the test as far as hydraulic conductivity becomes constant.

\section{ACKNOWLEDGEMENT}

The authors thank the Indonesian Directorate General of Higher Education (DIKTI), the Sultan Agung Islamic University Indonesia, the Ministry of Education and Training of Vietnam and the University of Danang Vietnam, for providing financial support for this work.
Chang, D.S. \& Zhang, L.M. 2011. A Stress-controlled erosion apparatus for studying internal erosion in soils.” J. ASTM Geotech Test. 34(6), 579-589

Chang, D.S. \& Zhang, L.M. 2013. Extended internal stability criteria for soils under seepage. Soils Found. 53(4): 569583.

Fell, R. \& Fry, J.J. 2013. Erosion in geomechanics applied to dams and levees. 1-99. Bonelli S. Editor. ISTE - Wiley.

Garner, S.J. \& Fannin, R.J. 2010. Understanding internal erosion: a decade of research following a sinkhole event. The International J. on Hydropower \& Dams 17: 93-98.

Ke, L. \& Takahashi, A. 2012. Strength reduction of cohesionless soil due to internal erosion induced by one dimensional upward seepage flow. Soils Found. 52(2012): 698-711.

Kenney, T.C. \& Lau, D. 1985. "Internal stability of granular filters". Can. Geotech. J. 22, 215-225.

Li, M. \& Fannin, J. 2008. Comparison of two criteria for internal stability of granular soil. Can. Geotech. J. 45: 13031309.

Luo, Y.L., Qiao, L., Liu, X.X., Zhan, M.L. \& Sheng, J.C. 2013. Hydro-mechanical experiments on suffusion under longterm large hydraulic heads. Nat. Hazards 65: 1361-1377.

Marot, D., Bendahmane, F., Rosquoët, F. \& Alexis, A. 2009. Internal flow effects on isotropic confined sand-clay mixtures. Soil \& Sediment Contamination, an International Journal 18(3): 294-306.

Marot, D., Bendahmane, F. \& Konrad, J.M. 2011a. Multichannel optical sensor to quantify particle stability un-der seepage flow. Can. Geotech. J. 48: 1772-1787.

Marot, D., Regazzoni, P.L. \& Wahl, T. 2011b. Energy based method for providing soil surface erodibility rankings. $J$. Geotech. Geoenviron. Eng. 137(12): 1290-1294.

Marot, D., Bendahmane, F. \& Nguyen, H.H. 2012. Influence of angularity of coarse fraction grains on internal erosion process. La Houille Blanche, International Water Journal 6: 47-53.

Moffat, R. \& Fannin, J. 2006. A large permeameter for study of internal stability in cohesionless soils. J. ASTM Geotech Test. 29(4): 273-279.

Nguyen, H.H., Marot, D. \& Bendahmane, F. 2012. Erodibility characterisation for suffusion process in cohesive soil by two types of hydraulic loading. La Houille Blanche, International Water Journal 6: 54-60.

Reddi, L.N., Lee, I. \& Bonala, M.V.S. 2000. Comparison of internal and surface erosion using flow pump test on a sandkaolinite mixture. J. ASTM Geotech Test. 23(1): 116-122.

Regazzoni, P.L. \& Marot, D. 2013. "A comparative analysis of interface erosion tests." Nat. Hazards 67(2): 937-950.

Sibille, L., Marot, D. \& Sail, Y. 2015a. A description of internal erosion by suffusion and induced settlements on cohesionless granular matter. Acta Geotechnica 10: 735-748.

Sibille, L., Lominé, F., Poullain, P., Sail, Y. \& Marot, D. 2015b. Internal erosion in granular media: direct numerical simulations and energy interpretation. Hydrol. Processes 29(9): 2149-2163.

Skempton, A.W. \& Brogan, J.M. 1994. Experiments on piping in sandy gravels. Géotechnique 44(3): 440-460.

\section{REFERENCES}

Bendahmane, F., Marot, D. \& Alexis, A. 2008. Experimental parametric Study of Suffusion and Backward Erosion. J. Geotech. Geoenviron. Eng. 134(1): 57-67. 